\title{
Future ready? Engaging learners and building transferable skills through authentic assessment and digital literacy
}

\author{
Jennifer Stokes \\ jennifer.stokes@unisa.edu.au \\ University of South Australia \\ John Pike \\ john.pike@unisa.edu.au \\ University of South Australia
}

Keywords: digital literacy, authentic assessment, transferable skills, enabling pedagogy, UDL.

\begin{abstract}
Students are excited by the possibilities presented through digital technologies and their applicability across a broad range of industries. Digital literacy has been identified as a foundational $21^{\text {st }}$ Century skill by the Australian Government (2020, p. 4), which is 'essential for individuals to participate effectively in today's society'. The need for strong transferable skills has accelerated during the pandemic as many industries have migrated to digital contexts. Digital literacy is a transferable skill sought after by employers, alongside other emerging transferable skills required for $21^{\text {st }}$ Century success, including critical thinking, creativity and problem-solving (FYA 2017, p. 8). In this paper, we will provide a case study of authentic assessment in an innovative digital literacy course at an Australian university, designed to support students from underrepresented backgrounds to build transferable skills for degree study and future careers.
\end{abstract}

Authentic assessment provides opportunities for meaningful learning as students complete assessments aligned with their aspirations and career interests: 'Authenticity automatically gives relevance to the learning journey; relevance encourages engagement and enthusiasm, which should bring about meaningful learning' (ACEL 2016). The scaffolded course design focuses on embedding professional practice through authentic assessment. Recent student projects include: an infographic of wellbeing techniques for children designed for educational contexts, an informative website to support refugees, a share-economy inspired app for deep cleaning, an infographic on sustainable architecture, a blog on brand development, and a review of robot programming for IT students. We will provide strategies for authentic assessment through technology-enhanced learning, which will offer insight and inspiration for educators interested in adopting these approaches.

Choice is a key element of course design, allowing students to demonstrate key concepts through the creation of unique and meaningful projects. First, students demonstrate threshold concepts, then they follow industry practice to pitch and produce an individual digital project. Course design is grounded in Universal Design for Learning (UDL) and enabling pedagogy (Stokes 2017). UDL techniques, including multiple modes of representation, action and expression, and engagement, support the learning of all students (CAST 2011). Enabling pedagogical approaches work to support the development of confidence, capability and agency, while valuing the strengths individual students bring (Stokes 2021). Students aiming for diverse fields have followed their interests to create digital projects aligned with their career aspirations, from game development to health apps, business sites to educational modules, critical digital reviews to music videos, animations to augmented and virtual reality content. Production work is negotiated with tutors, who provide guidance and mentorship, following a production company ethos. Students adhere to industry standards for copyright and ethical practice in assessments, while building their professional portfolio and skills for future success.

The combination of digital literacy and authentic assessments motivates students to follow their passions and create digital products they care about. This approach has resulted in outstanding student evaluations and learning outcomes, above average retention, and institutional recognition through a Digital Learning citation. Importantly, this approach supports students to build professional skills and knowledge for emerging industries and future career opportunities. 


\section{SCHOLARSHIP OF TECHNOLOGY ENHANCED LEARNING}

SoTEL Symposium 16-18 February 2022

\section{References}

ACEL. (2016). Authentic learning: what, why and how? e-Teaching, 10. http://www.acel.org.au/acel/ACEL_docs/Publications/e-Teaching/2016/e-Teaching_2016_10.pdf

Australian Government. (2020). Foundation Skills for Your Future Program: Digital Literacy Skills Framework, Canberra: Commonwealth of Australia.

Australian Technology Network. (2020). ATN joint statement on authentic assessment, Australian Technology Network. https://www.atn.edu.au/news-and-events/latest-news/atn-joint-statement-on-authentic-assessment

CAST. (2011). Universal Design for Learning Guidelines Version 2.0. Massachusetts: Wakefield.

Foundation for Young Australians (2017). The new work smarts. https://www.fya.org.au/report/the-new-worksmarts

Stokes, J. (2017). Inclusion and engagement by design: Creating a digital literacy course to inspire diverse learners in an Australian university enabling program. International Studies in Widening Participation, 4(2), 65-78. https://novaojs.newcastle.edu.au/ceehe/index.php/iswp/article/download/85/103

Stokes, J. (2021). Those skills to take on the world: developing capitals through university enabling programs. The International Journal of Learning in Higher Education, 28 (2), 133-146. DOI: 10.18848/2327$\underline{7955 / \mathrm{CGP} / \mathrm{v} 28 \mathrm{i} 02 / 133-146}$ 